J. Clin. Chem. Clin. Biochem.

Vol. 28, 1990, pp. 379-390

(C) 1990 Walter de Gruyter \& Co. Berlin $\cdot$ New York

\title{
Cholecystokinin and Glucose-Induced Insulinaemia in Dogs With and Without Pancreatic Acinar Atrophy
}

\author{
By Regina H. Meister, Ines H. Berger and P. O. Schwille \\ Division of Experimental Surgery and Endocrine Research Laboratory, Department of Surgery, University of \\ Erlangen, West Germany
}

(Received August 15, 1989/February 12, 1990)

\begin{abstract}
Summary: The entero-insular hormonal axis was studied in eleven conscious Beagle dogs, loaded with glucose orally and intravenously. In five of them, exocrine pancreatic atrophy was induced by pancreatic duct occlusion with prolamine, and documented by means of the $p$-amino-benzoic acid test. After oral glucose, the duct-occluded dogs displayed higher blood glucose ( $\log$ area $4.12 \pm 0.07$ versus $3.76 \pm 0.10 ; p<0.01$ ), less plasma insulin ( $\log$ area $3.56 \pm 0.08$ versus $3.99 \pm 0.08 ; \mathrm{p}<0.01$ ) and less cholecystokinin-like immunoreactivity $(\log$ area $2.64 \pm 0.09$ versus $3.10 \pm 0.14 ; \mathrm{p}<0.01)$ than controls. In controls, the peripheral venous insulin concentrations were higher after oral than after isoglycaemic intravenous glucose, and this difference was no longer demonstrable in duct-occluded dogs. In the latter, gel permeation chromatography of pool plasma after oral glucose revealed a relative decrease of cholecystokinin-like immunoreactivity species, which eluted at the positions of sulphated cholecystokinin octapeptide, cholecystokinin-33 and cholecystokinin39 , and at a position intermediate between these two. Also in the duct-occluded animals, intravenous infusion of sulphated cholecystokinin octapeptide, in addition to oral glucose, resulted in an increase in plasma insulin ( $\log$ area $3.83 \pm 0.10$ versus $3.64 \pm 0.06 ; \mathrm{p}<0.01$ ) and an improvement in oral glucose tolerance. It is concluded that in the dog
\end{abstract}

1) the absence of pancreatic acinar tissue is associated with a loss of gastrointestinal factors mediating glucoseinduced insulin secretion, and

2) reduction of circulating endogenous cholecystokinin species may account at least in part for this defect.

\section{Introduction}

Peripheral venous insulin concentrations are higher after enteral than after parenteral administration of glucose, with both routes producing an equal rise in blood glucose levels. This effect reflects part of the regulatory influence of some intestinal factors upon pancreatic islet functions, known as the "entero-insular axis" (1). Gastric inhibitory polypeptide (or glucose-dependent insulinogenic peptide) is so far the best characterized enteric peptide involved in this effect $(1,2)$, and it may be not the only one $(3-5)$.

On the other hand, the combination of gastric inhibitory polypeptide and cholecystokinin ${ }^{1}$ ) produced a marked increase in the insulin secretory response of isolated perifused rat islets in the presence of adequately elevated glucose in the medium (6), an effect that could be confirmed in the isolated perfused rat pancreas using much smaller doses of cholecystokinin33 and gastric inhibitory polypeptide (7).

An in vivo stimulation of insulin secretion by cholecystokinin was proposed years ago (8), and since has been supported by numerous direct and indirect ob-

\footnotetext{
1) cholecystokinin-8S = sulphated cholecystokinin octapeptide cholecystokinin-8 = non-sulphated cholecystokinin octapeptide

cholecystokinin $-4=$ cholecystokinin tetrapeptide cholecystokinin-33/39/58 = cholecystokinin (containing 33, 39,58 amino acids, respectively)
} 
servations: cholecystokinin receptors are located on the B-cell (9), exogenous cholecystokinin increases glucose-induced insulin secretion from islets in vitro $(10-13)$, caerulein and highly purified neutral cholecystokinin stimulate insulinaemia in the dog (14), mouse (15), and rat (16). However, for the dog, no data are available on the liberation of endogenous cholecystokinin by glucose, and its possible molecular nature.

The present study was performed in a Beagle dog model with long-term exocrine pancreatic insufficiency brought about by duct occlusion by prolamine and subsequent loss of the entero-insular axis of insulin, as demonstrated earlier (17). We evaluated

1) the peripheral blood levels of endogenous cholecystokinin in association with the proved lack of glucose-mediated insulin secretion in occluded dogs;

2) the gel chromatographic characteristics of circulating cholecystokinin;

3) the effect of exogenous administration of sulphated cholecystokinin octapeptide, which is supposed to possess the full biological activity of cholecystokinin, on oral glucose tolerance and glucose-mediated insulin in the insulin-deficient dogs with pancreatic duct occlusion.

\section{Materials and Methods}

Animals

Eleven male Beagle dogs with a body weight between 15 and $30 \mathrm{~kg}$, were used after training to Pavlov stands. They were kept in a controlled environment, had a daily outdoor run, and were under the supervision of a veterinarian. They were fed once per day with commercial laboratory diet (Dog meal, Latz Purina, Emskirchen; FRG) and tap water ad libitum. Surgical preparations had been performed 3 years previously (17): pancreatic duct occlusion $(n=5)$ by means of an alcoholic prolamine gel (Ethibloc, Ethicon, Norderstedt; FRG), resulting in complete atrophy of the exocrine pancreas (18), and shamoperation $(n=6)$ by laparotomy only. Since surgery, all animals received pancreatic enzymes (Pankreon, Kali-Chemie, Hannover; FRG), $3 \mathrm{~g}$ orally once per day (1 $\mathrm{g}$ represents 12,000 FIP units lipase, 9,000 FIP units amylase, 800 FIP units proteases). None of the dogs had developed steatorrhea or any sign of intestinal malabsorption during the 36 months observation period. All function tests were performed with conscious animals after deprivation of food and enzymes for $24 \mathrm{~h}$.

\section{Experimental protocol}

\section{Exocrine pancreatic function test}

The acinar atrophy of the pancreas was monitored by indirect evaluation of the digestive capacity using the $p$-amino-benzoic acid test, which was adapted to the $\operatorname{dog}(19)$ and based on serial measurement of $p$-amino-benzoic acid in serum (20). Blood samples were drawn from an antecubital vein at $-20,-10$, $30,60,90,120,150,180,210 \mathrm{~min}$. Citrate plasma $(0.1 \mathrm{ml} \mathrm{Na}-$ citrate per $\mathrm{ml}$ blood) was deproteinised with trichloroacetic acid $(100 \mathrm{~g} / \mathrm{l})$, and supernatants were stored at $-20^{\circ} \mathrm{C}$ until analysis.

\section{Glucose loads}

Oral glucose tolerance was tested by the intragastric instillation of $1.5 \mathrm{~g} / \mathrm{kg}$ body weight glucose (dissolved in $100 \mathrm{ml}$ distilled water). Intravenous glucose was injected as a $400 \mathrm{~g} / 1$ solution into a hindleg vein, using an infusion pump; the dose was adjusted to produce the same glucose concentration as that recorded previously in the oral glucose tolerance test in the same animal; for this purpose it was necessary to monitor the blood glucose in intervals of 2-5 min. Blood samples were drawn from an antecubital vein at $-30,-20,-10,15,30,45$, $60,75,90,120,150,180$ min into pre-chilled tubes containing $1.2 \mathrm{~g}$ EDTA and $500 \cdot 10^{3} \mathrm{KIU}$ aprotinin per litre of blood. Plasma was stored at $-20{ }^{\circ} \mathrm{C}$ until analysis.

\section{Exogenous cholecystokinin}

Animals with pancreatic duct occlusion $(n=4)$, showing insulin deficiency in the oral glucose tolerance test (see Results, section 2 ), underwent two additional oral glucose tolerance tests with either intravenous administration of cholecystokinin-8S (Bachem, Bubendorf; Switzerland), $0.05 \mu \mathrm{g} / \mathrm{kg}$ body weight (40 $\mathrm{pmol} / \mathrm{kg})$ at $0 \mathrm{~min}$, and subsequent infusion of $0.06 \mu \mathrm{g}(50$ $\mathrm{pmol}) / \mathrm{kg} \cdot \mathrm{h}$ over $2 \mathrm{~h}$ at a rate of $12 \mathrm{ml} / \mathrm{h}$, or the corresponding volume of vehicle (see below). The cholecystokinin concentration measured by radioimmunoassay (see below) at the tube outlet multiplied by the infusion rate yielded an amount of transported peptide that was always close to the indicated calculated dose. The indicated dose was chosen from our own pilot experiments and literature data, showing that in the dog infusion of $24 \mathrm{pmol} / \mathrm{kg} \cdot \mathrm{h}$ and in man infusion of $109 \mathrm{pmol} /$ $\mathrm{kg} \cdot \mathrm{h}$ produced plasma levels equivalent to $9-10 \mathrm{ng} / \mathrm{l}$ and approx. $7 \mathrm{ng} / 1$ of standard cholecystokinin-8S, respectively, above the baseline, when both doses were monitored by bioassay $(22,23)$. For comparison, the increasse of plasma cholecystokinin-like immunoreactivity above the baseline, as achieved with $50 \mathrm{pmol} / \mathrm{kg} \cdot \mathrm{h}$ cholecystokinin-8S in the present work, was higher by a factor $1.5-2$ (see Results), thereby indicating that our radioimmunoassay (see below) does not underestimate the circulating cholecystokinin-like immunoreactivity after the intravenous infusion of this peptide. The vehicle consisted of a $1: 10(\mathrm{v}: \mathrm{v})$ mixture of $0.15 \mathrm{~mol} / \mathrm{l} \mathrm{NaCl}$ and dog serum freed of cholecystokinin-like immunoreactivity by $30 \mathrm{~g} / 1$ microfine precipitated silica (QUSO G 32, Bie \& Berntsen, Aarhus; Denmark). Cholecystokinin-8S was chosen for this protocol because initial studies revealed that it is no less insulinogenic than cholecystokinin-33 on a molar basis. Others (21) have also reported that synthetic cholecystokinin-8S, natural canine cholecystokinin-33/39 and cholecystokinin-58 have equal biological potency.

\section{Chromatography}

The cholecystokinin-like immunoreactivity (analysis see below) detectable in plasma after oral glucose loading was separated into different molecular species using gel filtration (column 1.6 $\times 90 \mathrm{~cm}$; Sephadex G 50 superfine, Pharmacia, Uppsala; Sweden). In order to prevent degradation, aggregation and noncovalent binding of cholecystokinin peptides, the column was eluted at $4{ }^{\circ} \mathrm{C}$ with $6 \mathrm{~mol} / \mathrm{l}$ urea in $0.1 \mathrm{~mol} / \mathrm{l}$ acetic acid. Dextran Blue and $\mathrm{Na}^{125} \mathrm{I}$ were used to label the void $\left(\mathrm{V}_{\mathrm{o}}\right)$ and total $\left(\mathrm{V}_{\mathrm{i}}\right)$ volume, and insulin $\left(M_{\mathrm{r}} 6000\right)$, cholecystokinin-33 $\left(M_{\mathrm{r}} 3919\right)$, cholecystokinin-8S $\left(M_{\mathrm{r}}\right.$ 1143) as markers of peptide elution. The positions of column markers and of cholecystokinin-like immunoreactivity in unknown samples (see below) were expressed as the distribution coefficients $\left(\mathrm{K}_{\mathrm{d}}\right)$. Owing to shortage of sample material, only four pool samples were processed [8.4 $\mathrm{ml}$ each, made up of plasma aliquots from four sham-operated and four duct-occluded dogs, respectively], all containing the peak of cholecystokinin-like immunoreactivity at 60,75 and 90 min after oral glucose loading. One sample from sham-operated and one from duct-occluded dogs were extracted (see below), lyophilized and reconstituted in $2.1 \mathrm{ml}$ eluent. Reconstituted 
sample $(1.5 \mathrm{ml})$ was applied to the column, and the remaining $0.6 \mathrm{ml}$ was assayed directly to monitor recovery from column. In order to assess whether extraction removes all plasma constituents interfering unspecifically in the cholecystokinin assay (see below) the other two pool samples from both groups were first stripped with charcoal (Norit A, Serva, Heidelberg; FRG). Stripping (130 g charcoal per litre of plasma) completely removed tracer non-sulphated cholecystokinin octapeptide (cholecystokinin-8) and cholecystokinin-8S added to plasma. Extracts of stripped plasma were then prepared, and assayed both before and after chromatography, as described above for extracts of unstripped plasma. In both preparations of the stripped plasma, i.e. material loaded on to the column and material eluted from the column, the concentration of cholecystokinin-like immunoreactivity was below the detection limit of the assay (see below). Thus, the assay was apparently free of unspecific interference, and no further reference will be made to this in the subsequent text. The stable flow rate was $6 \mathrm{ml} / \mathrm{h}$ (Microperpex pump, LK B Instruments, Bromma; Sweden), the eluate volume $2 \mathrm{ml}$. Recovery of cholecystokinin-like immunoreactivity from the column was $95-105$ per cent, after correction for the assay detection limit. Gastrin was not detectable (see also below) in the eluates obtained under these conditions

\section{Analyses}

p-Amino-benzoic acid was measured by the Bratton-Marshall method (as modified by Freudiger (26) et al. (19)), glucose by glucose oxidase (Gluco-Analyzer, Beckman, Fullerton; USA). Radioimmunoassay procedures were used for the determination of insulin (plasma (24)), gastrin (plasma (25)), gastric inhibitory polypeptide [using antibody coded AE 96 (26), and following essentially the procedure described by the same company], and cholecystokinin-like immunoreactivity. The latter was extracted from plasma with 75-90 per cent efficiency by two volumes of ethanol (analytical values for unknown samples are quoted without correction). The carboxyl-terminal cholecystokinin assay, which recognizes the sulphated tyrosyl regions of cholecystokinin species, which in turn confer bioactivity to target organs, has been described previously (27). The rabbit cholecystokinin antibody (code C, final dilution 1:100000) shows almost the same molar sensitivity for detection of cholecystokinin-8S and natural cholecystokinin-33 (recognition sites amino acid residues $28-29$ ), but it is much less sensitive in the detection of (non-sulphated) cholecystokinin-8 and synthetic (sulphated) human gastrin-17, as indicated by the relative molar peptide concentrations capable of displacing 20 per cent of antibody-bound tracer (taking standard cholecystokinin-8S as 1.0): cholecystokinin-33 0.85 , non-sulphated cholecystokinin-8 2.7, cholecystokinin- 425 , gastrin-17 10 . Thus it should be noted that cholecystokinin-like immunoreactivity values in plasma represent a mixture mainly of cholecystokinin-8S and cholecystokinin-33. Within the framework of our experiments the slight cross-reactivity with gastrin was negligible, because: gastrin peptides are only poorly extracted from plasma by ethanol (approximately 25 per cent); on a molar basis the rise of serum gastrin in response to glucose loading is relatively small (fig. 2 ); and gastrin does not bind to the cholecystokinin antibody in an acidic and urea-containing environment (see above; chromatography). Initially, extracts of hormone-free dog plasma (see above) were added to the standard curve tubes in amounts equivalent to tubes containing the unknowns; no change of the interaction of the standard reference material with the antibody was observed. The mean sensitivity of the cholecystokinin assay (10 runs), expressed as per cent tracer binding in the absence of standard material minus 2 standard deviations, was $2 \mathrm{pg}$. The immunoreactivities of hormones correspond to picogramequivalents of the respective standard. Detection limits were (per $\mathrm{ml}$ plasma): insulin $2 \mu \mathrm{U}$, gastrin $3 \mathrm{pg}$; cholecystokininlike immunoreactivity $5 \mathrm{pg}$ (corresponding to $<1.2 \mathrm{pmol} / \mathrm{l}$ cholecystokinin-33 and approx. $4.5 \mathrm{pmol} / \mathrm{l}$ cholecystokinin-8S). Inter- and intra-assay variation coefficients were $<12 \%$.
Calculations and statistics

The difference between the blood levels of hormones after oral and intravenous glucose loading was considered to reflect the influence of the entero-insular axis. Integrated values were calculated from areas above the mean of three baseline values using the computerized parabolic method. All values are given as means + SEM, unless otherwise noted. Based on the distribution type of values the significance of differences $(p<0.05)$ was tested by the non-parametric U-test or by the t-test for paired and non-paired observations (28), as appropriate.

\section{Results}

\section{General clinical data 36 months after pan-} creatic duct occlusion

All animals showed normal eating and drinking behaviour throughout the observation period, the mean body weight in sham-operated dogs increasing from $17.9 \pm 1.2 \mathrm{~kg}$ (preoperatively) to $21.0 \pm 1.9 \mathrm{~kg}$, in duct-occluded dogs from $16.2 \pm 0.6 \mathrm{~kg}$ (pre-operatively) to $18.5 \pm 1.4 \mathrm{~kg}$. Fasting blood glucose (shamoperated dogs: $5.22 \pm 0.06 \mathrm{mmol} / \mathrm{l}$; duct-occluded dogs: $5.33 \pm 0.06 \mathrm{mmol} / \mathrm{l})$, fasting insulin concentrations (see below), and glucose concentration in spot urines (sham-operated dogs: $1.11 \pm 0.06 \mathrm{mmol} / \mathrm{l}$; duct-occluded dogs: $1.00 \pm 0.06 \mathrm{mmol} / \mathrm{l})$ did not differ significantly between the two groups. The $p$ amino-benzoic acid test as an indicator of the proteolytic capacity of the exocrine pancreas was significantly reduced in all duct-occluded dogs (fig. 1).

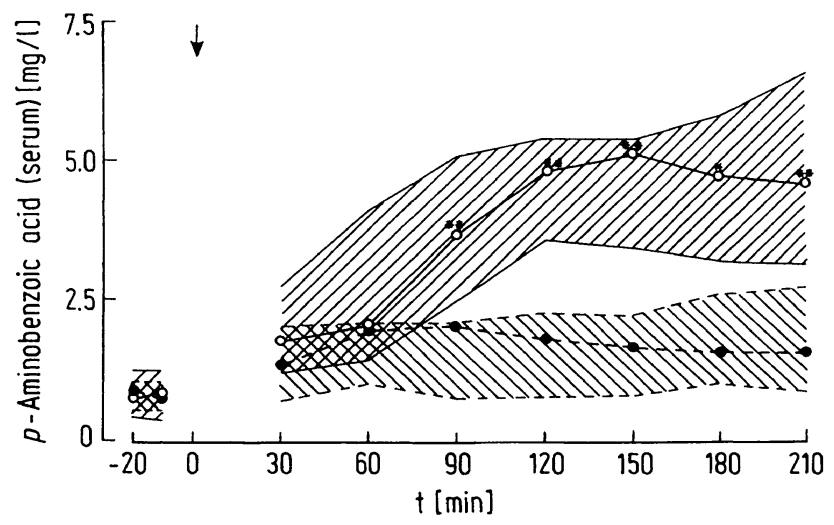

Fig. 1. p-Amino-benzoic acid test for indirect evaluation of the exocrine pancreatic function in Beagle dogs 36 months after pancreatic duct occlusion ( $\mathrm{n}=5, \bullet-\bullet)$ and shamoperated controls $(n=6 ; 0-0)$. Median and range (hatched areas) of individual values. $\downarrow$ : application of test meal.

${ }^{*} \mathrm{p}<0.05$; $* * \mathrm{p}<0.01$; sham-operated versus ductoccluded dogs

2. Plasma glucose and hormones in response to glucose loads (fig. 2)

\section{Oral glucose load}

In sham-operated dogs plasma glucose increased from the basal level $(5.27 \pm 0.06 \mathrm{mmol} / \mathrm{l})$ to $10.71 \pm 0.61$ 

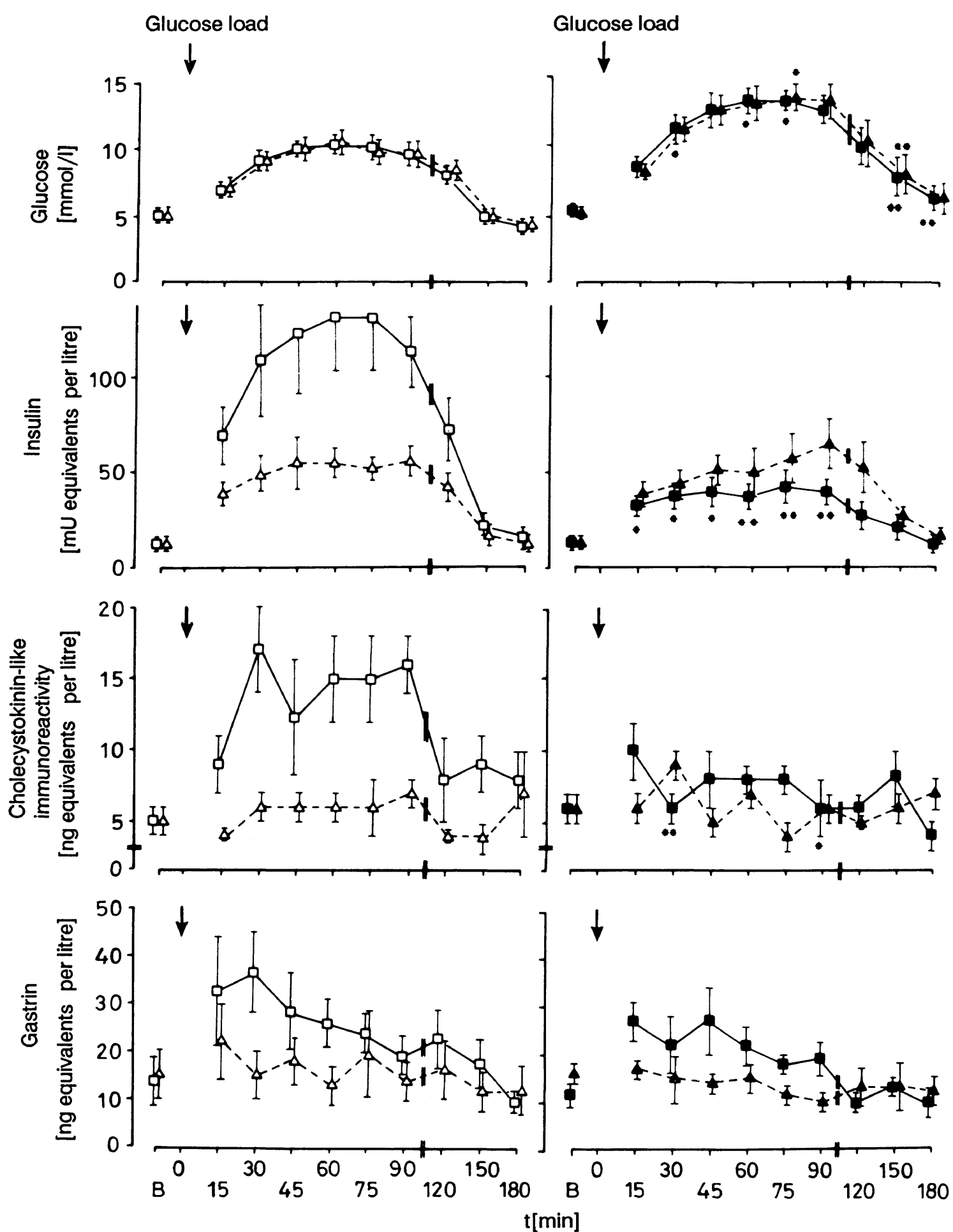

Fig. 2. Patterns of blood glucose, insulin, cholecystokinin-like immunoreactivity and gastrin after glucose load ( $\downarrow)$ in dogs with pancreatic duct occlusion $(n=5 ; \mathbf{a}-\mathbf{a}$ oral glucose; $\boldsymbol{\Delta}--\boldsymbol{\Delta}$ intravenous glucose) or sham-operated ( $\mathrm{n}=6$; $\square-\square$ oral glucose; $\Delta---\Delta$ intravenous glucose). Glucose concentrations observed with oral glucose approximated closely to those obtained by intravenous glucose (for details see Methods section). Means \pm SEM.

$* \mathrm{p}<0.05 ;{ }^{* *} \mathrm{p}<0.01$; duct-occluded versus sham-operated dogs

$\mathrm{mmol} / \mathrm{l}$ at $60 \mathrm{~min}$, in duct-occluded dogs from basal $(5.55 \pm 0.06 \mathrm{mmol} / \mathrm{l})$ to $14.15 \pm 1.00 \mathrm{mmol} / \mathrm{l}(60$ $\mathrm{min})$. At $30,60,75,150,180 \mathrm{~min}$ the glucose concentration was significantly higher in duct-occluded dogs than in sham-operated dogs. Plasma insulin increased from $12 \pm 2 \mathrm{mU} / 1$ (basal) to $131 \pm 27 \mathrm{mU} / 1(60 \mathrm{~min})$ in sham-operated dogs. At 15 until 90 min the duct- occluded dog group displayed significantly lower insulin concentrations (basal $8 \pm 2 \mathrm{mU} / \mathrm{l}$; peak $43 \pm 9$ $\mathrm{mU} / 1$ at $75 \mathrm{~min}$ ) than the sham-operated dogs group. Basal plasma cholecystokinin-like immunoreactivity was $5 \pm 1$ (sham-operated dogs) and $6 \pm 1$ (ductoccluded dogs) ng/l, respectively. In sham-operated dogs plasma cholecystokinin-like immunoreactivity 
peaked twice $(17 \pm 2 \mathrm{ng} / \mathrm{l}$ at $30 \mathrm{~min} ; 16 \pm 2 \mathrm{ng} / \mathrm{l}$ at $90 \mathrm{~min}$ ). Between 30 and $120 \mathrm{~min}$ the cholecystokininlike immunoreactivity pattern in the duct-occluded dog group was at a lower mean level than in the sham-operated dog group $(6 \pm 1 \mathrm{ng} / 1, \mathrm{p}<0.01$, and $6 \pm 2 \mathrm{ng} / \mathrm{l}, \mathrm{p}<0.05$, at 30 and $90 \mathrm{~min}$, respectively). In the sham-operated dog group plasma gastrin increased from basal $(14 \pm 5 \mathrm{ng} / \mathrm{l})$ to $37 \pm 9 \mathrm{ng} / \mathrm{l}$ at 30 min, in the duct-occluded dog group from basal $(12 \pm 3 \mathrm{ng} / \mathrm{l})$ to $27 \pm 3 \mathrm{ng} / \mathrm{l}$ (differences not significant). Basal as well as peak values of plasma gastric inhibitory polypeptide did not differ significantly in the sham-operated dogs and duct-occluded dog group (basal: $46 \pm 1$ and $51 \pm 2 \mathrm{ng} / \mathrm{l}$; peak: $958 \pm 145$ and $989 \pm 162 \mathrm{ng} / \mathrm{l}$, respectively).

\section{Intravenous glucose load}

Basal plasma glucose before intravenous glucose load was in the same range as before oral glucose load (sham-operated dogs: $5.22 \pm 0.11 \mathrm{mmol} / 1$; duct-occluded dogs: $5.33 \pm 0.11 \mathrm{mmol} / \mathrm{l})$. Figure 2 shows that the mean glucose values obtained under oral glucose load closely approximated to the values, obtained by intravenous glucose administration, using the technique described in the Methods section. The insulin concentration did not differ significantly between sham-operated dogs and duct-occluded dogs throughout the intravenous glucose load (basal level: sham-operated dogs $13 \pm 3 \mathrm{mU} / \mathrm{l}$; duct-occluded $\operatorname{dogs} 8 \pm 1 \mathrm{mU} / \mathrm{l})$.

Until 120 min the sham-operated dog group displayed $30-50 \%$ less insulin under intravenous than under oral glucose load. In contrast, the insulin pattern in the duct-occluded dog group did not differ significantly between intravenous and oral glucose load. Plasma cholecystokinin-like immunoreactivity did not increase significantly over the basal level in either the sham-operated dog group $(5 \pm 1 \mathrm{ng} / \mathrm{l}$; peak $7 \pm 1 \mathrm{ng} / \mathrm{l}$ at $90 \mathrm{~min}$ ) or the duct-occluded dog group (basal $6 \pm 1 \mathrm{ng} / \mathrm{l}$; peak $6 \pm 1 \mathrm{ng} / \mathrm{l}$ at $90 \mathrm{~min}$ ). In both groups plasma gastrin did not rise significantly above the basal level (sham-operated dogs: $15 \pm 5 \mathrm{ng} / \mathrm{l}$; ductoccluded dogs: $16 \pm 2 \mathrm{ng} / \mathrm{l}$ ). In sham-operated dogs, up to $75 \mathrm{~min}$ after receiving glucose, the gastrin concentrations were lower under intravenous than under oral glucose load ( $\mathrm{p}<0.05$ at 30 and $60 \mathrm{~min}$ ). A similar difference was observed in the duct-occluded dog group up to $90 \mathrm{~min}$ after receiving glucose $(\mathrm{p}<0.01$ at 75 and $60 \mathrm{~min} ; \mathrm{p}<0.05$ at $90 \mathrm{~min}$ ). Plasma gastric inhibitory polypeptide did not significantly rise above the basal level in both groups (52 \pm 1 and $46 \pm 2 \mathrm{ng} / \mathrm{l}$ in sham-operated and ductoccluded dogs, respectively).
3. Integrated glucose and hormones under the glucose loads (tab. 1)

Under oral, as well as under intravenous glucose load, duct-occluded dogs displayed significantly increased integrated glucose compared with sham-operated dogs. Also under oral glucose load, integrated insulin and cholecystokinin-like immunoreactivity were significantly decreased in the duct-occluded dogs compared with the sham-operated dog group, whereas under intravenous glucose load no difference in the

Tab. 1. Integrated values of plasma glucose, insulin, cholecystokinin-like immunoreactivity (cholecystokinin) and gastrin in pancreatic duct-occluded $(n=5)$ and shamoperated $(n=6)$ Beagle dogs after oral and intravenous glucose; the dose of the latter was adapted so as to mirror glucose values observed with the former. Means \pm SEM.

\begin{tabular}{|c|c|c|c|}
\hline Analyte & $\begin{array}{l}\text { Dog } \\
\text { group }\end{array}$ & $\begin{array}{l}\text { Oral } \\
\text { glucose load } \\
\text { log area/180 min }\end{array}$ & $\begin{array}{l}\text { Intravenous } \\
\text { glucose load } \\
\text { log area } / 180 \mathrm{mir}\end{array}$ \\
\hline \multirow[t]{2}{*}{ Glucose } & $\begin{array}{l}\text { Sham- } \\
\text { operated }\end{array}$ & $3.765 \pm 0.101$ & $3.794 \pm 0.092$ \\
\hline & $\begin{array}{l}\text { Duct- } \\
\text { occluded }\end{array}$ & $4.122 \pm 0.074^{* *}$ & $4.144 \pm 0.089^{*}$ \\
\hline \multirow[t]{2}{*}{ Insulin } & $\begin{array}{l}\text { Sham- } \\
\text { operated }\end{array}$ & $3.988 \pm 0.079$ & $3.571 \pm 0.065$ \\
\hline & $\begin{array}{l}\text { Duct- } \\
\text { occluded }\end{array}$ & $3.557 \pm 0.077^{* *}$ & $3.735 \pm 0.070$ \\
\hline \multirow{2}{*}{$\begin{array}{l}\text { Chol- } \\
\text { ecysto- } \\
\text { kinin }\end{array}$} & $\begin{array}{l}\text { Sham- } \\
\text { operated }\end{array}$ & $3.098 \pm 0.143$ & $2.585 \pm 0.086$ \\
\hline & $\begin{array}{l}\text { Duct- } \\
\text { occluded }\end{array}$ & $2.645 \pm 0.095^{* *}$ & $2.517 \pm 1.164$ \\
\hline \multirow[t]{2}{*}{ Gastrin } & $\begin{array}{l}\text { Sham- } \\
\text { operated }\end{array}$ & $3.590 \pm 0.078$ & $3.327 \pm 0.143$ \\
\hline & $\begin{array}{l}\text { Duct- } \\
\text { occluded }\end{array}$ & $3.553 \pm 0.052$ & $3.303 \pm 0.105$ \\
\hline
\end{tabular}

${ }^{* *} \mathrm{p}<0.01$ (duct-occluded versus sham-operated dogs)

levels of the two hormones could be found. In the sham-operated dog group the integrated gastrin was significantly higher under oral than under intravenous glucose load. Also in the sham-operated dog group, the mean integrated gastrin was higher under oral than under intravenous glucose load, but in the ductoccluded dog group neither integrated gastrin nor integrated gastric inhibitory polypeptide (data not shown) differed statistically under oral and intravenous glucose load. 


\section{Entero-insular axis (tab. 2)}

The quantitation of the effect of the entero-insular axis was reflected by the difference $(\triangle)$ between hormone concentrations as obtained under oral and intravenous glucose load. The duct-occluded dog group displayed significantly decreased $\Delta$ insulin and $\triangle$ cholecystokinin-like immunoreactivity when compared with the sham-operated dog group. $\triangle$ gastrin did not differ significantly between the sham-operated dogs and duct-occluded dog group. The integrated $\triangle$ insulin and $\Delta$ cholecystokinin-like immunoreactivity were significantly decreased in the latter, whereas integrated $\Delta$ gastrin did not differ statistically between the two groups. In the sham-operated dog group there was a significant positive correlation between the mean values of $\Delta$ cholecystokinin-like immunoreactivity and $\Delta$ insulin $(r=0.744 ; p<0.01)$, and between the median values of $\triangle$ gastrin and $\triangle$ insulin $(r=0.787 ; p<0.01)$. In the duct-occluded dog group such correlations were lacking.

5. Chromatography of cholecystokinin-like immunoreactivity in plasma extracts

Total cholecystokinin-like immunoreactivity, extracted from pool plasma obtained during oral glucose load was $143 \mathrm{pg}$ and $103 \mathrm{pg}$, for the shamoperated dogs and duct-occluded dog group, respectively. Regarding the apparent nature of this cholecystokinin-like immunoreactivity, three components were identified, eluting at positions corresponding to the $M_{\mathrm{r}}$ of cholecystokinin-58 $\left(\mathrm{K}_{\mathrm{d}} 0.27\right)$, cholecystokinin-33/39 ( $\mathrm{K}_{d}$ 0.46/0.54), and cholecystokinin-8S $\left(\mathrm{K}_{\mathrm{d}}\right.$ 0.83) (tab. 3). The absolute (in pg) and relative (in per cent) contribution of these species to the total plasma cholecystokinin-like immunoreactivity after oral glucose load in the two plasma samples indicate that in the duct-occluded dog group species of lower $M_{\mathrm{r}}$ (cholecystokinin-33/39; cholecystokinin-8) were decreased, whereas species of higher $M_{\mathrm{r}}$ (cholecystokinin-58 and above), were increased (tab. 3). It should be noted that there were, in addition to the peaks corresponding to established cholecystokinin molecular species, five intermediate peaks (designated $I_{1}-I_{5}$ ), emerging between the $V_{0}$ marker and cholecystokinin-58 $\left(\mathrm{I}_{1}\right)$, the latter and cholecystokinin-33/ $39\left(\mathrm{I}_{2}\right)$, cholecystokinin-33/39 and cholecystokinin-8S $\left(\mathrm{I}_{3}, \mathrm{I}_{4}\right)$, cholecystokinin-8S and the $\mathrm{V}_{\mathrm{i}}$ marker $\left(\mathrm{I}_{5}\right)$; in both plasma samples the contribution by these intermediate peaks to the total cholecystokinin-like immunoreactivity was greater than that of established cholecystokinins. In contrast, the reduction (in pg) of cholecystokinin-like immunoreactivity arising from

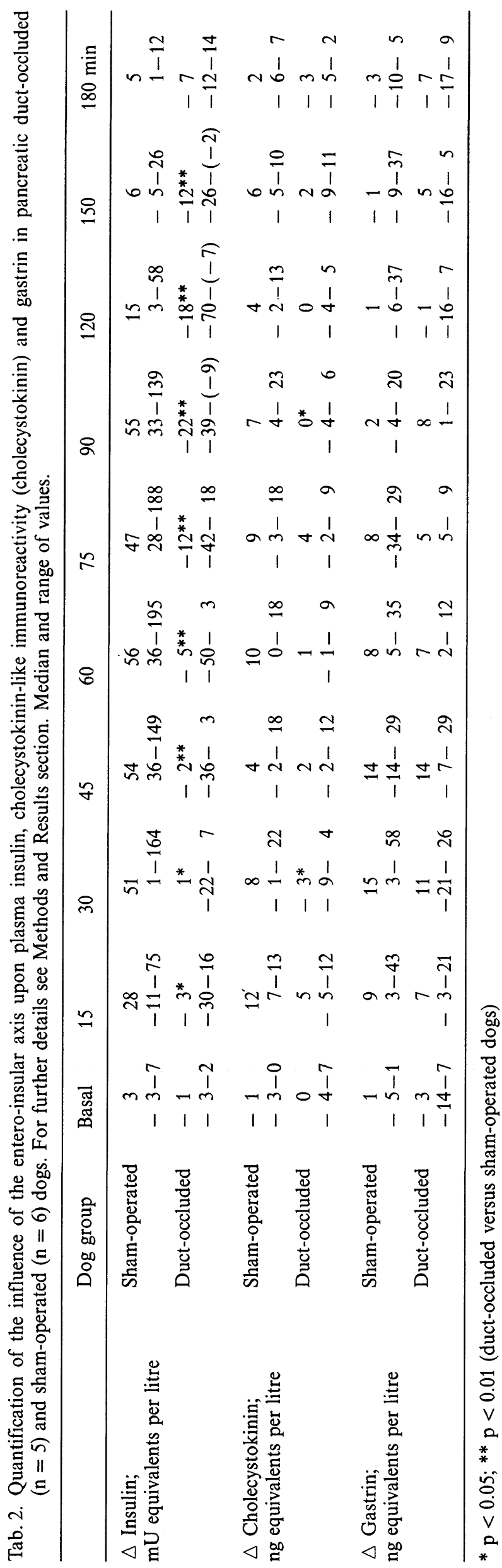


Tab. 3. Gel permeation chromatography of cholecystokinin (CCK) immunoreactive molecular species in one plasma pool sample recruited from dogs with pancreatic duct occlusion and one sample recruited from sham-operated control animals; the two samples correspond to the observation points where the respective plasma samples contained the highest cholecystokinin immunoreactivity concentrations after oral glucose load $(60,75,90 \mathrm{~min})$. The total cholecystokinin-like immunoreactivity eluted was 144.3 and $101.9 \mathrm{pg}$ for the samples from sham-operated and duct-occluded dogs, respectively. I: intermediate peak; for further details see Methods and Results section. The graph underlying the data of this table is available upon request from the corresponding author.

\begin{tabular}{|c|c|c|c|c|c|c|c|c|c|}
\hline & Dog group & $I_{1}$ & CCK-58 & $\mathrm{I}_{2}$ & $\begin{array}{l}\text { CCK-39 } \\
\text { CCK-33 }\end{array}$ & $\begin{array}{l}\mathrm{I}_{3} \\
\mathrm{CCK}-25 ?\end{array}$ & $\begin{array}{l}\mathrm{I}_{4} \\
\mathrm{CCK}-18 ?\end{array}$ & CCK-8 & $\mathrm{I}_{5}$ \\
\hline \multicolumn{10}{|c|}{ Cholecystokinin-like immunoreactivity } \\
\hline \multirow[t]{2}{*}{ pg equivalents } & $\begin{array}{l}\text { Sham- } \\
\text { operated }\end{array}$ & 30.3 & 6.1 & 11.3 & 27.8 & 20.9 & 18.4 & 23.5 & 6.0 \\
\hline & $\begin{array}{l}\text { Duct- } \\
\text { occluded }\end{array}$ & 17.8 & 8.5 & 17.7 & 9.5 & 11.9 & 9.1 & 15.9 & 11.5 \\
\hline \multirow[t]{2}{*}{$\%$} & $\begin{array}{l}\text { Sham- } \\
\text { operated }\end{array}$ & 21 & 4 & 8 & 19 & 15 & 13 & 16 & 4 \\
\hline & $\begin{array}{l}\text { Duct- } \\
\text { occluded }\end{array}$ & 18 & 8 & 17 & 9 & 12 & 9 & 16 & 11 \\
\hline
\end{tabular}

the long-term pancreatic duct occlusion, as depicted in figure 2, was approximately 33 per cent of both the intermediate and the established peaks.

6. Plasma glucose and hormones in response to exogenous cholecystokinin-8S in pancreatic duct-occluded dogs (fig. 3, tab. 4)

Plasma glucose increased from the basal level (5.11 \pm 0.06 and $5.11 \pm 0.17 \mathrm{mmol} / \mathrm{l})$ to $11.43 \pm 1.33$ $\mathrm{mmol} / \mathrm{l}(60 \mathrm{~min})$ and $13.93 \pm 1.94 \mathrm{mmol} / \mathrm{l}(60 \mathrm{~min})$ under cholecystokinin-8S and vehicle, respectively. Under cholecystokinin-8S, duct-occluded dogs displayed a tendency to lower plasma glucose than under vehicle. There was a 3.5 -fold $(15 \mathrm{~min})$ and $1.5-2$ fold (until $90 \mathrm{~min}$ ) increase in the insulin concentration under cholecystokinin-8S compared with vehicle (basal values: vehicle $12 \pm 2 \mathrm{mU} / \mathrm{l}$; cholecystokinin$8 \mathrm{~S} 16 \pm 2 \mathrm{mU} / \mathrm{l})$. The mean insulin in sham-operated dogs under oral glucose load (fig. 3; dotted line) could not, however, be attained. Within the $2 \mathrm{~h}$ infusion period plasma cholecystokinin-like immunoreactivity reached a plateau of $11 \pm 1 \mathrm{ng} / \mathrm{l}$ at $15 \mathrm{~min}$ after the start of infusion (basal level: $6 \pm 1 \mathrm{ng} / \mathrm{l}$, under both cholecystokinin-8S and vehicle), but the attained plasma cholecystokinin-like immunoreactivity remained below the level of that observed for endogenous cholecystokinin-like immunoreactivity in the sham-operated dog group under oral glucose load (which was taken as the physiological reference; fig. 3 , dotted line). Therefore, an infusion delivering a higher dose of cholecystokinin-8S [bolus $0.05 \mu \mathrm{g} / \mathrm{kg}$, infusion $0.09 \mu \mathrm{g}(75 \mathrm{pmol}) / \mathrm{kg} \cdot \mathrm{h}]$ was run together with oral glucose load. After achieving steady-state, the mean plasma cholecystokinin-like immunoreactivity values exceeded those obtained in the sham-op- erated dog group, but insulinaemia and glucose tolerance could not be further improved (data not shown). Linear regression analysis of the mean plasma cholecystokinin-like immunoreactivity and insulin resulted in a positive correlation $(\mathrm{r}=0.752 ; \mathrm{p}<0.001)$. Under cholecystokinin-8S infusion the integrated glucose was significantly decreased $(p<0.01$ and $\mathrm{p}<0.05$, respectively; tab. 4), when compared with data obtained by vehicle infusion.

\section{Discussion}

The results of the study show that exocrine pancreatic atrophy following pancreatic duct occlusion in the dog was associated in the long-term with normal body weight, provided that daily enzyme substitution was maintained. In this situation there were no overt signs of diabetes. Thus, in the fasting state glucose levels in blood and urine, as well as plasma insulin levels, never showed any deterioration. However, when enzymes were discontinued (e.g. before commencement of the present experiments) the $p$-amino-benzoic acid test definitely discriminated duct-occluded dogs with exocrine pancreatic atrophy from dogs with an intact pancreas (fig. 1), as documented previously (18). During the experiments, the insulin data in sham-operated dogs confirmed the well-known difference in peripheral plasma insulin concentration between oral and isoglycaemic intravenous glucose load, whereas ductoccluded dogs displayed increased plasma glucose and deficient plasma insulin under oral glucose load. This lack of insulin in the duct-occluded dogs versus the sham-operated dog group (fig. 2) points to an impairment of the insulinogenic effect of glucose normally elicited by the gut under oral glucose load (1). 


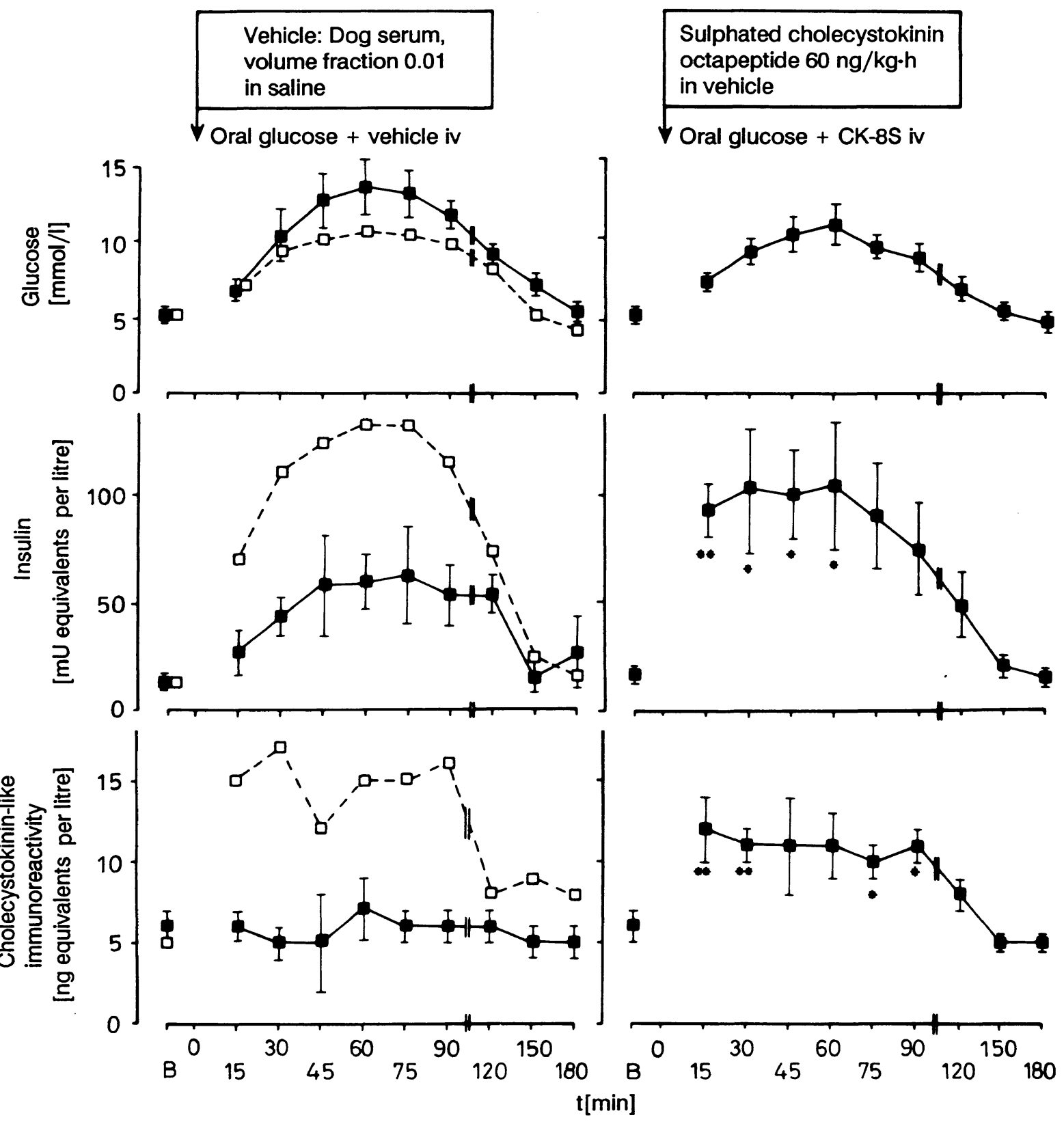

Fig. 3. Patterns of blood glucose, insulin and cholecystokinin-like immunoreactivity in pancreatic duct occluded dogs $(\mathrm{n}=4$; - - ) after oral glucose load with either intravenous bolus injection of $8 \mathrm{~S}(\downarrow)$ and subsequent infusion of cholecystokinin$8 \mathrm{~S}$ for $2 \mathrm{~h}$, or oral glucose with intravenous bolus injection of vehicle $(\downarrow)$ and subsequent infusion of vehicle for $2 \mathrm{~h}$. The respective mean values as observed in sham-operated controls after oral glucose load are given for comparison ( $\square---\square)$. Means \pm SEM.

$* \mathrm{p}<0.05 ; * * \mathrm{p}<0.01$; cholecystokinin-8S versus vehicle

Tab. 4. Integrated values of plasma glucose, insulin and cholecystokinin-like immunoreactivity (cholecystokinin) in pancreatic duct-occluded dogs $(n=4)$ after oral glucose superimposed by intravenous bolus and infusion of sulphated cholecystokinin octapeptide (cholecystokinin-8S), or after oral glucose superimposed by intravenous bolus and infusion of vehicle (vehicle). Means \pm SEM.

\begin{tabular}{lll}
\hline & $\begin{array}{l}\text { Vehicle } \\
\text { log area/180 min }\end{array}$ & $\begin{array}{l}\text { Cholecystokinin-8S } \\
\text { log area/180 min }\end{array}$ \\
\hline Glucose & $4.082 \pm 0.054$ & $3.821 \pm 0.088^{* *}$ \\
Insulin & $3.643 \pm 0.058$ & $3.834 \pm 0.101$ \\
Cholecystokinin & $2.619 \pm 0.263$ & $3.081 \pm 0.071^{*}$ \\
\hline
\end{tabular}

${ }^{*} \mathrm{p}<0.05 ; * * \mathrm{p}<0.01$ versus vehicle
Available literature data focus on a contributory role of circulating cholecystokinin in the control of blood glucose homeostasis $(9,10,22,29)$. The decreased plasma cholecystokinin-like immunoreactivity that was associated with a deficit in glucose-induced insulin in pancreatic duct-occluded dogs, and the subtotal restoration of normal insulin and glucose concentrations and intravenous substitution of cholecystokinin-8S (fig. 3) provide evidence that cholecystokinin is a mediating factor in glucose-induced insulin secretion in these dogs. Calculation of the difference between individual values under oral and intravenous glucose load $(\triangle)$ directly yielded values for the gut- 
mediated portion of total insulin, as well as the portion of total cholecystokinin-like immunoreactivity that may be responsible for the former. Sham-operated dogs displayed significantly more $\Delta$ insulin in combination with significantly increased $\Delta$ cholecystokinin-like immunoreactivity, than duct-occluded dogs. Also, the significant positive correlation between $\triangle$ cholecystokinin-like immunoreactivity and $\triangle$ insulin seen only in sham-operated dogs supports the hypothesis that cholecystokinin may have mediated the increased insulin secretion in these dogs. Insulin secretion and oral glucose tolerance in the duct-occluded dog group could not be further improved by infusion of higher doses of cholecystokinin$8 \mathrm{~S}$, which resulted in even higher-than-normal plasma cholecystokinin-like immunoreactivity (see Results section). This observation suggests that cholecystokinin-8S (as well as gastric inhibitory polypeptide; see Introduction) might be not the only mediator(s) of glucose-induced insulin secretion, at least in these pancreatic duct-occluded dogs. Participation of molecular species of cholecystokinin other than cholecystokinin-8S has to be considered, since especially species of intermediate $M_{\mathrm{r}}$ appeared to be decreased in the duct-occluded dog group (see below). Of the species with intermediate $M_{\mathrm{r}}$, the insulinogenic potency of infused cholecystokinin-33 was no higher than that of cholecystokinin-8S in the duct-occluded dog group under oral glucose load (data not shown); other species, however, were not available to us for infusion.

Thus, it cannot be excluded that the combined infusion of cholecystokinin-8S and cholecystokinin-33/39, or of cholecystokinin-8S and cholecystokinin species yet to be defined, would yield different results with respect to insulinogenity. The combined infusion of cholecystokinin-8S and gastric inhibitory polypeptide was considered to be inappropriate, because the response of plasma levels of gastric inhibitory polypeptide during either oral or intravenous glucose load did not differ between the sham-operated dogs and ductoccluded dog group (see Results, sections 2, 3).

It is necessary to mention that the evaluation of a gastrointestinal peptide with regard to insulinogenity demands the comparison of an oral glucose load with an isoglycaemic intravenous glucose load in the same individual. In our model cholecystokinin-like immunoreactivity showed all criteria claimed for a gastrointestinal hormone involved in glucose-induced insulin secretion (1):

1) release by food, especially glucose;

2) stimulation of insulin secretion in the presence of elevated blood glucose;
3) plasma concentrations achieved by exogenous infusion did not exceed those obtained after oral food.

Also, recent reports show that oral glucose $(29,30)$ and sucrose (30) release cholecystokinin-like immunoreactivity, exogenous cholecystokinin releases insulin in the presence of adequate plasma levels of glucose in vitro $(10-13)$, as well as in vivo in the rat (16) and mouse (15), and finally specific receptors are located in the islets of Langerhans in the region of Bcells (9). Thus, from the available information, our results on the insulinogenic properties of cholecystokinin-like immunoreactivity under oral glucose load are in agreement with independent observations on the role of cholecystokinin in glucose homeostasis.

In agreement with previous investigators (31), we were able to demonstrate in dog plasma, using gel permeation chromatography, the existence of three peaks of cholecystokinin-like immunoreactivity corresponding to the $M_{\mathrm{r}}$ of cholecystokinin-8S, cholecystokinin-33/ 39 , and cholecystokinin- 58 . Recently, so-called intermediate peaks of cholecystokinin-like immunoreactivity positioned between those of cholecystokinin-8S and cholecystokinin-33/39 were detected (32); these were specified in the dog and thought to represent cholecystokinin-18 and cholecystokinin-25(32). In the present study, the intermediate peaks of cholecystokinin-like immunoreactivity with $M_{\mathrm{r}}$ smaller than cholecystokinin-58 $\left(\mathrm{I}_{2}-\mathrm{I}_{5} ;\right.$ tab. 3$)$ theoretically could have resulted from enzymatic in vitro degradation of cholecystokinin- 58 at basic $\mathrm{pH}$ (the $\mathrm{pH}$ of the cholecystokinin assay buffer was $8.2 ;(27))$. The nature of the peak $\mathrm{I}_{1}$ eluting before cholecystokinin- 58 cannot be interpreted; it could represent cholecystokinin precursor material or aggregates of smaller fragments. In order to gain further insight, more studies, including use of appropriate standard reference peptides and or region-specific antibodies, are necessary. Any possible cross-reaction of the cholecystokinin antibody with gastrin structures, should these have been present in the fractions in measurable amounts, had been excluded by the failure of these to react in the gastrin assay (see Methods section). Also the chromatography was carried out under dissociating conditions. Thus it appears that in the peripheral plasma of the dog loaded with oral glucose there may exist a cholecystokinin species bigger than cholecystokinin-58 $\left(M_{\mathrm{r}}>6000\right)$. Other authors (33) also reported a peak located close to $\mathrm{V}_{\mathrm{o}}$, detectable by both $\mathrm{COOH}$ - and $\mathrm{NH}_{2}$-oriented antibodies in acid extracts of pig brain cortex, after gel filtration on Sephadex G-50 sf using acidic $(0.1 \mathrm{~mol} / \mathrm{l} \mathrm{HCl})$ column eluent.

We have no adequate explanation for the presence of the circulating molecular species of cholecystokinin 
possibly responsible for the enhanced plasma insulin levels after oral glucose load in the sham-operated dog group, and its absence in the duct-occluded dog group of our dogs. The overall cholecystokinin-like immunoreactivity was decreased by approx. 30 per cent in the latter group. Since in this duct-occluded dog group there is a 2 -fold increase in the percentage of cholecystokinin-58, in addition to a fall of the values of biologically active cholecystokinin-33/39 and of the intermediate forms $\left(\mathrm{I}_{3}, \mathrm{I}_{4}\right)$, it is possible that the degradation of cholecystokinin-58 is impaired under these conditions; with respect to insulin release, the biological activity of cholecystokinin-58 is unknown.

Whether gastrin participates in the glucose-mediated secretion of insulin is not yet clarified. Exogenous gastrin in nearly physiological doses potentiated the plasma insulin concentration under oral glucose load (34). The results of our present study in the dog agree with recent observations in man (35): an immediate but small increase in plasma gastrin under oral glucose load, as compared with no gastrin change under intravenous glucose load (fig. 2). From this and other observations on gastrin (see Results), gastrin would appear to play little if any part in the control of the gut-mediated regulation of peripheral insulin levels in the dog.

\section{Concluding remarks}

A present, the effect of greater insulin concentrations after oral than after intravenous glucose load, but with an equal blood glucose concentration under both regimes, seems to be mediated by a combination of increased secretion and decreased clearance of insulin (36); increased secretion is possibly induced by one or several of the following hormones: gastric inhibitory peptide, cholecystokinin, gastrin, glucagon-likepeptide 1 (37). Our study provides more specific data on insulin changes brought about by experimentally induced alterations of cholecystokinin, which is under discussion as a possible insulinogenic agent $(9,10,22$, 29). Previously, no animal model was available that lacked gut-mediated insulin release. The dog with pancreatic duct occlusion and acinar atrophy is therefore the first suitable model for studies on this condition. A possible limitation of this model is that the intragastric instillation of glucose bypasses the cephalic phase of insulin release which is determined by the cholinergic vagal tone; also, vagal cholinergic stimulation sensitizes $B$ cells in response to ingestion of glucose (38). The decreased insulin and impaired oral glucose tolerance in the presence of pancreatic exocrine insufficiency, as demonstrated in this study, has been known for the duct ligated dog for about 15 years (39), and the same phenomenon was confirmed for duct occlusion-mediated insufficiency in more recent studies in this species $(17,40)$. In contrast, rats with exocrine pancreatic atrophy display normal or even improved oral glucose tolerance and insulin secretion, regardless of the technique in use for inducing exocrine insufficiency $(42-44)$. One may speculate the pancreas functions differ in some species, for example, with regard to regulation of cholecystokinin release. Thus, cholecystokinin-mediated feedback of pancreatic enzyme secretion exists in the rat (45), but not in the dog with acinar atrophy owing to pancreatic duct obliteration (46), and its presence is controversial in man $(47,48)$. In summarizing our data, we can conclude that in the dog

1) endogenous cholecystokinin qualifies as a mediator of glucose-induced insulin secretion;

2) the relative insulinogenic effects of different molecular species of cholecystokinin-like immunoreactivity circulating in blood after oral glucose load are uncertain, but there is evidence that cholecystokinin$33 / 39$ and fragments intermediate between these and cholecystokinin-8S are the predominant insulinogenic species.

\section{Acknowledgements}

We thank $K$. Schwille and B. Schreiber for technical assistance, and I. Goldberg for typing the manuscript. The study was supported by Deutsche Forschungsgemeinschaft (Schw 210/42), and the Erlangen University Hospital Research funds.

\section{References}

1. Creutzfeldt, W. (1975) The incretion concept today. Diabetologia 16, $75-85$.

2. Dupré, J., Ross, S. A., Watson, D. \& Brown, J. C. (1973) Stimulation of insulin secretion by gastric inhibitory polypeptide in man. J. Clin. Endocrinol. Metab. 37, 826-828.

3. Ebert, R. \& Creutzfeld, W. (1982) Influence of gastric inhibitory polypeptide antiserum on glucose-induced insulin secretion in rats. Endocrinology 111, 1601-1606.

4. Ebert, R., Unger, H. \& Creutzfeldt, W. (1983) Preservation of incretin activity after removal of gastric inhibitory polypeptide (GIP) from rat gut extracts by immunoabsorption. Diabetologia 24, 449-454.

5. Sarson, D. L., Wood, S. M., Holder, D. \& Bloom, S. R. (1982) The effect of glucose-dependent insulinotropic polypeptide infused at physiological concentrations on the release of insulin in man. Diabetologia 22, 33-36. 
6. Zawalich, W. S. (1988) Synergistic impact of cholecystokinin and gastric inhibitory polypeptide on the regulation of insulin secretion. Metabolism 37, 778-781.

7. Sandberg, E., Ahrén, B., Tendler, D. \& Efendic, S. (1988) Cholecystokinin-33 potentiates and vasoactive intestinal polypeptide inhibits gastric inhibitory polypeptide-induced insulin secretion in the perfused rat pancreas. Acta Endocrinol. 117, 545-551.

8. Unger, R. H., Ketterer, H., Dupré, J. \& Eisentraut, A. M. (1967) The effect of secretin, pancreozymin and gastrin on insulin and glucagon secretion in anaesthetized dogs. $J$. Clin. Invest. 46, 630-645.

9. Verspohl, E. J., Ammon, H. P. T., Williams, J. A. \& Goldfine, I. D. (1986) Evidence that cholecystokinin interacts with specific receptors and regulates insulin release in isolated rat islets of Langerhans. Diabetes 35, 38-43.

10. Hermansen, K. (1981) Effects of cholecystokinin (CCK)-4, nonsulfated $\mathrm{CCK}-8$, and sulfated $\mathrm{CCK}-8$ on pancreatic somatostatin, insulin, and glucagon secretion in the dog: studies in vitro. Endocrinology 114, 1770-1775.

11. Otsuki, M., Okabayashi, Y., Ohki, A., Oka, F., Fujii, M., Nakamura, T., Sajuiura, N., Yanaihara, N. \& Baba, S. (1986) Action of cholecystokinin analogues on exocrine and endocrine rat pancreas. Am. J. Physiol. 250, G405-G411.

12. Sakamoto, C., Otsuki, M., Ohki, A., Yuu, H., Maeda, M., Tomio, Y. \& Baba, S. (1982) Glucose-dependent insulinotropic action of cholecystokinin and caerulein in the isolated perfused rat pancreas. Endocrinology 110, 398-402.

13. Zawalich, W. S., Cote, S. B. \& Diaz, V. A. (1986) Influence of cholecystokinin on insulin output from isolated perfused pancreatic islets. Endocrinology 119, 616-621.

14. Frame, C. M., Davidson, M. B. \& Sturdevant, R. A. L. (1975) Effects of the octapeptide of cholecystokinin on insulin and glucagon secretion in the dog. Endocrinology $97,549-533$.

15. Ahren, B., P. Hedner, I. \& Lundquist, I. (1986) Effects of six cholecystokinin (CCK) fragments on insulin secretion in the mouse. Acta Pharmacol. Toxicol. 58, 115-120.

16. Sźecowka, J., Lins, P. E. \& Effendic, S. (1982) Effects of cholecystokinin, gastric inhibitory polypeptide, and secretion on insulin and glucagon secretion in rats. Endocrinology $110,1268-1272$.

17. Schwille, P. O., Engelhardt, W., Gumbert, E., Gebhardt, C. \& Gall, F. P. (1984) Long-term pancreatic duct occlusion impairs the entero-insular axis in the dog - failure of plasma VIP to respond as "incretin". Peptides 4, 445-450.

18. Gebhardt, C. \& Stolte, M. (1978) Pankreasgang-Okklusion durch Injektion einer schnellhärtenden Aminosäurelösung. Langenbecks Arch. Chir. 346, 149-166.

19. Freudiger, U. \& Bigler, B. (1973) Die Diagnose der chronischen exokrinen Pankreasinsuffizienz mit dem PABA-Test. Kleintierpraxis 22, 73-79.

20. Tanner, A. R. \& Robinson, D. P. (1988) Pancreatic function testing: serum PABA measurement is a reliable and accurate measurement of exocrine function. Gut 29, 1736-1740.

21. Eysselein, V. E., Deveney, C. W., Sankaran, H., Reeve jr., J. R. \& Walsh, J. H. (1983) Biological activity of canine intestinal cholecystokinin-58. Am J. Physiol. 245, G313G320.

22. Liddle, R. A., Rushakoff, R. J., Morita, E. T., Beccaria, L., Carter, J. D. \& Goldfine, I. D. (1988) Physiological role for cholecystokinin in reducing postprandial hyperglycemia in humans. J. Clin. Invest. 81, 1675-1681.

23. Sakamoto, T., Fujimura, M., Newman, I., Zhu, X. G., Greeley, jr., G. H. \& Thompson, I. C. (1985) Comparison of hepatic elimination of different forms of cholecystokinin in dogs. J. Clin. Invest. 75, 280-285.

24. Herbert, V., Lau, L., Gottlieb, C. W. \& Bleicher, S. J. (1965) Coated charcoal immunoassay of insulin. J. Clin. Endocrinol. Metab. 25, 1375-1384.
25. Stadil, F. \& Rehfeld, F. (1973) Determination of gastrin in serum. An evaluation of the reliability of radioimmunoassay. Scand. J. Gastroenterol. 80,101-112.

26. Cambridge Research Biochemicals Ltd, Harston; UK: Technical note on "Peptide Antisera" (1987).

27. Meister, R. H., Anetsberger, R., Berger, I. \& Schwille, P. O. (1988) Improvement of oral glucose tolerance in the dog by feeding trypsin inhibitor. Role of the entero-insular axis. Scand. J. Gastroenterol. 23, 679-686.

28. Sachs, L. (1972) Statistische Auswertungsmethoden, Springer, Heidelberg.

29. Liddle, R. A., Goldfine, J. D., Roden, M. S., Taplitz, R. A. \& Williams, J. A. (1985) Cholecystokinin bioactivity in human plasma. J. Clin. Invest. 75, 1144-1152.

30. Douglas, B. R., Woutersen, W. A., Jansen, J. B. J. J., de Jong, A. J. L. \& Lamers, C. B. H. W. (1988) The influence of different nutrients on plasma cholecystokinin levels in the rat. Experientia 44, 21-23.

31. Eysselein, V. E., Böttcher, W., Kaufmann jr., G. L. \& Walsh, J. H. (1984) Molecular heterogeneity of canine cholecystokinin in portal and peripheral plasma. Regul. Pept. 9, $173-185$

32. Jansen, J. B. M. J. \& Lamers, C. B. H. W. (1987) Molecular forms of cholecystokinin in plasma from normal and gastrectomized human subjects following a fat meal. Peptides 8, 801-807

33. Eng, I., Shina, Y., Straus, E. \& Yalow, R. S. (1982) Posttranslational processing of cholecystokinin in pig brain and gut. Proc. Natl. Acad. Sci., USA 79, 6060-6064.

34. Rehfeld, J. F. \& Stadil, F. (1973) The effect of gastrin on basal- and glucose-stimulated insulin secretion in man. $J$. Clin. Invest. 52, 1415-1426.

35. Shuster, L. D., Go, V. L. W., Rizza, R. A., O’Brien, P. C. \& Service, F. J. (1988) Potential incretins. Mayo Clin. Proc. 63, 794-800.

36. Shuster, L. T., Go, V. L. W., Rizza, R. A., O'Brian, P. C. \& Service, F. J. (1988) Incretin effect due to increased secretion and decreased clearance of insulin in normal humans. Diabetes 37, 200-203.

37. Kreymann, B., Ghatei, M. A., Williams, G. \& Bloom, S. R. (1987) Glucagon-like peptide 1 (7-36): A physiological incretin in man. Lancet $I I, 1300-1303$.

38. Trimble, E. R., Berthoud, H. R., Siegel, E. C., Jeanrenaud, B. \& Renold, A. F. (1981) Importance of cholinergic innervation of the pancreas for glucose tolerance in the rat. Am. J. Physiol. 241, 337-341.

39. Ambromovage, A. M., Pairent, F. W. \& Howard, J. M (1973) Pancreatic exocrine insufficiency: The effects of longterm pancreatic duct ligation on serum insulin levels and glucose metabolism in the dog. Ann. Surg. 177, 338-323.

40. Gooszen, H. G., Bosman, F. T. \& van Schilfgaarde, R (1984) The effect of duct obliteration on the histology and endocrine function of the canine pancreas. Transplantation $38,13-17$

41. Williamson, P., Deane, S. A., Ekberg, H., Hawthorne, W J., Garvey, J. F. W., Stewart, G. J., Eastman, C. J. \& Little, J. M. (1988) Long-term canine duct-occluded segmental pancreatic autografts: endocrine function. Pancreas 3 , $646-652$

42. Isaksson, G., Ihse, I. \& Lundquist, I. (1983) Influence of pancreatic duct ligation on endocrine and exocrine rat pancreas. Acta physiol. Scand. 117, 281-286.

43. Klein, P., Engelhardt, W., Stolte, M., Schwille, P. O. \& Neidhardt, J. (1984) Pancreatic duct occlusion in the rat - Short-term effects on oral glucose tolerance and shortand long-term effects on hormone content of the pancreas. Eur. Surg. Res. 16, 15-22.

44. Tomita, T., Thodes, J., Falscroft, J., Doull, V., Kimmel, J. R. \& Pollok, H. G. (1988) Endocrine pancreas in the rat model of exocrine pancreatic insufficiency. Pancreas 3 , $568-575$ 
45. Dexter, S. L., May, D., Miller, P. \& Owyang, D. (1986) Cholecystokinin mediates feedback regulation of pancreatic enzyme secretion in rats. Am. J. Physiol. 250, G252-G259.

46. Van der Burg, M. P. M., Gooszen, H. G., Guicherit, O. R. Jansen, J. B. M. J., Frölich, M., van Haastert, F. A. \& Lamers, C. B. H. W. (1989) Contribution of partial pancreatectomy, systemic hormone delivery, and duct obliteration of glucose regulation in canine pancreas. Importance in pancreas transplantation. Diabetes $38,1082-1089$.
47. Cantor, P., Petronijevic, L. \& Worning, H. (1986) Plasma cholecystokinin concentrations in patients with advanced chronic pancreatitis. Pancreas $1,488-493$.

48. Slaff, J. I., Wolfe, M. M. \& Toskes, P. P. (1985) Elevated fasting cholecystokinin levels in pancreatic exocrine impairment: evidence to support feedback regulation. J. Lab. Clin. Med. 105, 282-285.

Prof. Dr. Dr. Paul O. Schwille

University Hospital

Department of Surgery

Maximiliansplatz 2

D-8520 Erlangen 